\title{
A Numerical Simulation on Phase Change of Steam in a Microchannel Condenser
}

\author{
Minhhung Doan ${ }^{1}$, Thaison Le ${ }^{1}$, Thanhtrung Dang ${ }^{1}$, and Jyh-tong Teng ${ }^{2}$ \\ ${ }^{1}$ Department of Thermal Engineering, HCMC University of Technology and Education, Vietnam \\ ${ }^{2}$ Department of Mechanical Engineering. Chung Yuan Christian Universitv. Chung-Li 32023, Taiwan \\ Email: hungdm@hcmute.edu.vn, trungdang@hcmute.edu.vn
}

\begin{abstract}
The heat transfer characteristics of a microchannel condenser in the phase change from the vapor phase to the liquid phase depend on many factors such as the physical parameters of the working fluid, the cooling fluid, etc. In this paper, the numerical results are clearly presented for the condensation profile, the density change, and the temperature of condensed water. Based on the results in this study, a function was suggested for predicting a relationship between the temperature of condensed water and the mass flow rate of steam from $0.01 \mathrm{~g} / \mathrm{s}$ to $0.1 \mathrm{~g} / \mathrm{s}$. Moreover, the results of numerical simulation are in good agreement with the experimental data. In addition, the results showed that the condensation profile is not strongly affected the gravitational force.
\end{abstract}

Keywords: Micro channels, heat transfer, temperature profile, condensation, steam.

\section{Introduction}

Micro technology is widely used by scientists in heat exchangers. Their results are getting better and better, such as increasing heat transfer rate and reducing heat exchanger size. In relation to the field of microchannel heat transfer, Asadi et al. [1] reviewed heat transfer and pressure drop characteristics of single and two-phase microchannels. They found that choosing a reasonable and proper mixture viscosity correlation is crucial to a successful interpretation of the two-phase frictional pressure drop data. We also reviewed to promote the effects of microchannel thermal efficiency. Xia and Chan [2] studied the effect of heat transfer using micro channel. In this study, a simulation model was established using computational fluid dynamics (CFD) and a new design of heat exchanger was proposed based on these extra micro-effects. The results showed that as the inlet area decreases, the heat transfer rate increases and the pressure loss decreases. Dang et al. [3-5] investigated the comparisons of the heat transfer and pressure drop of the microchannel and minichannel heat exchangers, both numerically and experimentally. The heat transfer rate obtained from microchannel heat exchanger is higher than that obtained from the minichannel heat exchanger; however, the pressure drop obtained from microchannel heat exchanger is also higher than that obtained from the minichannel heat exchanger. So, the microchannel heat exchanger should be selected for the systems where high heat transfer rates are needed. The impact of gravity on the fluid through the microchannel heat exchangers was found to be small, with the maximum difference between the two cases being less than $8 \%$. The heat flux of $17.38 \times 10^{4} \mathrm{~W} / \mathrm{m}^{2}$ ( or $17.38 \mathrm{~W} / \mathrm{cm}^{2}$ ) was achieved for water from the hot side of the device having the inlet temperature of $70^{\circ} \mathrm{C}$ and mass flow rate of $0.2503 \mathrm{~g} / \mathrm{s}$ and for water from the cold side having the inlet temperature of $21.5^{\circ} \mathrm{C}$ and mass flow rate of $0.2906 \mathrm{~g} / \mathrm{s}$. In addition, the results obtained from numerical analyses were in good agreement with those obtained from experiments, with discrepancies of the heat transfer coefficient estimated to be less than $9 \%$.

Yu et al. [6] focused on the hydraulic and thermal characteristics of fractal tree-like microchannels by numerical and experimental methods. The experimental results showed that the fractal tree-like microchannels had a much higher heat transfer coefficient than that of straight microchannels at the cost of a much higher pump power. Fossa [7] built a simple model for evaluating the heat transfer and flow characteristics in annular two-phase flow. The model is applied to various flow conditions including thermal non equilibrium and variable cross section ducts. A modified k- $\varepsilon$ turbulence model was developed by $\mathrm{Hu}$ and Zhang [8] to simulate the gas-liquid two-phase flow and heat transfer in steam surface condensers, using a quasi-three-dimensional algorithm. The results obtained from the proposed 
model agree well with the experimental results. In addition, the results also show an obvious improvement in the prediction accuracy comparing with previous results where a constant value for the turbulent viscosity was used. A hybrid modeling approach was proposed by Ding et al. [9] to describe the dynamic behavior of the two phase flow condensers used in air-conditioning and refrigeration systems. The merits of model included: 1) it balances the trade-offs between complexity and accuracy; 2) the model order is very low; 3) all the state variables of the model are measurable. Mirzabeygi and Zhang [10, 11] developed a three-dimensional numerical model to simulate the fluid flow and heat transfer in industrial steam surface condensers with complex irregular shapes. The convective heat transfer correlations were used to model the heat and mass transfer between the shell-side fluid and the tube-side fluid. A modified RNG k- $\varepsilon$ turbulence model was used to account for the turbulence effects on the fluid flow and heat transfer in condensers. The effect of the turbulence and non-condensable gases on the primary phase flow was also included in the numerical model. The numerical results were compared with the experimental data for a small experimental condenser and a full-size industrial condenser, and the proposed numerical model was proved to be relatively accurate in simulating the turbulent twophase flows in condensers. The turbulence models from the $k-\varepsilon$ and $k-\omega$ families were assessed to select the most effective model for the simulation of two-phase flow and heat transfer in tube and shell condensers. In these studies, the k- $\omega$ SST had the best performance and the least error among different turbulence models.

The condensation flow of the refrigerant FC-72 in a rectangular microchannel with a 1-mm hydraulic diameter was numerically studied by Chen et al. [12] using the volume of fluid (VOF) model. In this study, the vapor phase formed a continuous column with a decreasing diameter downstream. Slugs were periodically generated at the head of the column. Decreasing the wall cooling heat flux and increasing the flow mass flux both increased the vapor column length. During condensation, the vapor velocity decreased down stream but was significantly higher than the adjacent liquid velocity. Ling et al. [13] presented a three dimensional direct simulation on boiling flow in a rectangular micro channel. Growth and merger of the bubbles were simulated and the impact of the bubbles' merger on the heat transfer was analyzed. In this study, the merger can produce a temporal growth in heat flux, while the thin liquid film between the bubble and the wall holds the main reason for the high heat flux in micro channel boiling flow. The condensation results and models were indicated in $[14,15]$. Doan and Dang [16] presented an experimental study on condensation in two horizontal micro channel condensers (M1 and M2) with different substrate and channel lengths. The mass flow rate of steam and pressure drop affected oscillation of condensation profile, beginning condensation point, and performance index. The heat transfer rate of model M1 was higher than that of model M2 at the same flow rate or pressure drop of steam. In addition, the pressure drop obtained from the micro channel condenser M1 was lower than that obtained from the micro channel condenser M2: at mass flow rate of $0.0264 \mathrm{~g} / \mathrm{s}$, the pressure drop of M1 was 1,257 $\mathrm{Pa}$ while the pressure drop of M2 was 6,105 Pa.

From the above studies, it has been shown that the phase change of steam in microchannel condenser was not numerically performed. So, it is essential to simulate on the phase change of steam in microchannel condenser by numerical simulation. The 3D simulation for the whole device will be carried out in this study which aimed to show the condensation profile in microchannels by evaluating the vapor quality change and density change. Besides, the 3D temperature profile for the whole device and the condenser water temperature at the outlet will be also considered. In addition, the equation for predicting the condenser water temperature at the outlet can be predicted by changing the vapor flow rate at the inlet at the same steam inlet and cooling water temperatures.

\section{Methodology}

\subsection{Mathematical Model}

To analyze condensation in the micro channel heat exchangers, there are several consumptions: continuum fluid and no radiation. The governing equations in this system can be expressed by [14].

Continuity equation 


$$
\frac{\partial \rho}{\partial t}+u \frac{\partial \rho}{\partial x}+v \frac{\partial \rho}{\partial y}+w \frac{\partial \rho}{\partial z}+\rho\left[\frac{\partial u}{\partial x}+\frac{\partial v}{\partial y}+\frac{\partial w}{\partial z}\right]=0
$$

Momentum equations

$$
\begin{aligned}
& \frac{\partial u}{\partial t}+u \frac{\partial u}{\partial x}+v \frac{\partial u}{\partial y}+w \frac{\partial u}{\partial z}=-\frac{1}{\rho} \frac{\partial p}{\partial x}+\frac{\mu}{\rho}\left(\frac{\partial^{2} u}{\partial x^{2}}+\frac{\partial^{2} u}{\partial y^{2}}+\frac{\partial^{2} u}{\partial z^{2}}\right) \\
& \frac{\partial v}{\partial t}+u \frac{\partial v}{\partial x}+v \frac{\partial v}{\partial y}+w \frac{\partial v}{\partial z}=-\frac{1}{\rho} \frac{\partial p}{\partial y}+\frac{\mu}{\rho}\left(\frac{\partial^{2} v}{\partial x^{2}}+\frac{\partial^{2} v}{\partial y^{2}}+\frac{\partial^{2} v}{\partial z^{2}}\right) \\
& \frac{\partial w}{\partial t}+u \frac{\partial w}{\partial x}+v \frac{\partial w}{\partial y}+w \frac{\partial w}{\partial z}=-\frac{1}{\rho} \frac{\partial p}{\partial z}+\frac{\mu}{\rho}\left(\frac{\partial^{2} w}{\partial x^{2}}+\frac{\partial^{2} w}{\partial y^{2}}+\frac{\partial^{2} w}{\partial z^{2}}\right)
\end{aligned}
$$

For steady-state conditions: $(\partial \rho / \partial t)=0,(\partial u / \partial t)=0,(\partial v / \partial t)=0$, and $(\partial w / \partial t)=0$

Where, $\mu$ is dynamic viscosity, $\rho$ is density, $u$ is velocity in the $\mathrm{x}$-direction, $v$ is velocity in the $\mathrm{y}$ direction, $w$ is velocity in the $\mathrm{z}$-direction, $p$ is pressure, and $p_{0}$ is initial pressure.

Besides, the heat transfer formulas were applied as [15]

Fourier's law for heat conduction

Heat transfer in solid

$$
\mathrm{q}=-\mathrm{k} . \nabla \mathrm{T}
$$

$$
\rho C_{p}\left(\frac{\partial T}{\partial t}+u_{\text {trans }} \cdot \nabla T\right)+\nabla \cdot\left(q+q_{r}\right)=-\alpha T: \frac{d S}{d t}+Q
$$

Heat transfer in liquid

$$
\rho C_{p}\left(\frac{\partial T}{\partial t}+u \cdot \nabla T\right)+\nabla \cdot\left(q+q_{r}\right)=\alpha_{p} T\left(\frac{\partial p}{\partial t}+u \cdot \nabla p\right)+\tau: \nabla u+Q
$$

Heat transfer in phase change from vapor to liquid can be determined by $\rho=\theta \rho_{p h 1}+(1-\theta) \rho_{p h 2}$ with $\theta$ being the vapor quality, and heat transfer coefficient $\alpha_{m}=\frac{1}{2} \frac{(1-\theta) \rho_{p h 2}-\theta \rho_{p h 1}}{\rho}$ (the mass fraction), where $\rho_{p h 1}$ and $\rho_{p h 2}$ are density of vapor and liquid, respectively.

The boundary conditions of heat transfer in phase change of the microchennal condenser are listed in Table 1.

Table 1. Boundary conditions [15].

\begin{tabular}{ll}
\hline Expression & Boundary conditions \\
\hline $\begin{array}{l}\text { Inlet of Steam and Cooling } \\
\text { water }\end{array}$ & $T=T_{0}$ \\
$\begin{array}{l}\text { Outlet of condensed water } \\
\text { and Cooling water }\end{array}$ & $-n(-k \nabla T)=0$ \\
$\begin{array}{l}\text { Mass flow rate of steam and } \\
\text { cooling water }\end{array}$ & $k=\frac{3}{2}\left(l_{T}\right)^{2}, \varepsilon=C_{\mu}^{3 / 4} \frac{k^{3 / 2}}{L_{T}}$ and $-\int_{\partial \Omega} \rho(u \cdot n) d_{b c} \cdot d S=m$ \\
& {$\left[-p I+\left(\mu+\mu_{T}\right)\left(\nabla u+(\nabla u)^{T}\right)-\frac{2}{3}\left(\mu+\mu_{T}\right)(\nabla u) \cdot I-\frac{2}{3} \rho k I\right] n=-\left(\hat{p}_{o}+p_{\text {hydro }}\right) n$} \\
& {$\left[\begin{array}{l}\text { Pressure } \\
\end{array}\right.$} \\
\hline
\end{tabular}

\subsection{Design and Numerical Simulation}

The experimental system for steam condensation in microchannel heat exchangers is shown in Fig. 1 [16]. The major component to observe in this system is microchannel condenser (1) with dimensions as shown in Fig. 2. This device consists of 10 square channels with $\mathrm{D}_{\mathrm{h}}=500 \mu \mathrm{m}$. Two PMMA (Polymethyl methacrylate) plates (Fig. 2b) with dimensions of $62 \times 14.5 \times 10(\mathrm{~mm})$ were pasted on the substrate. 
This model was set up and generated mesh with the Free Tetrahedral type and it included 48047 domain elements, 13927 boundary elements, and 3303 edge elements.

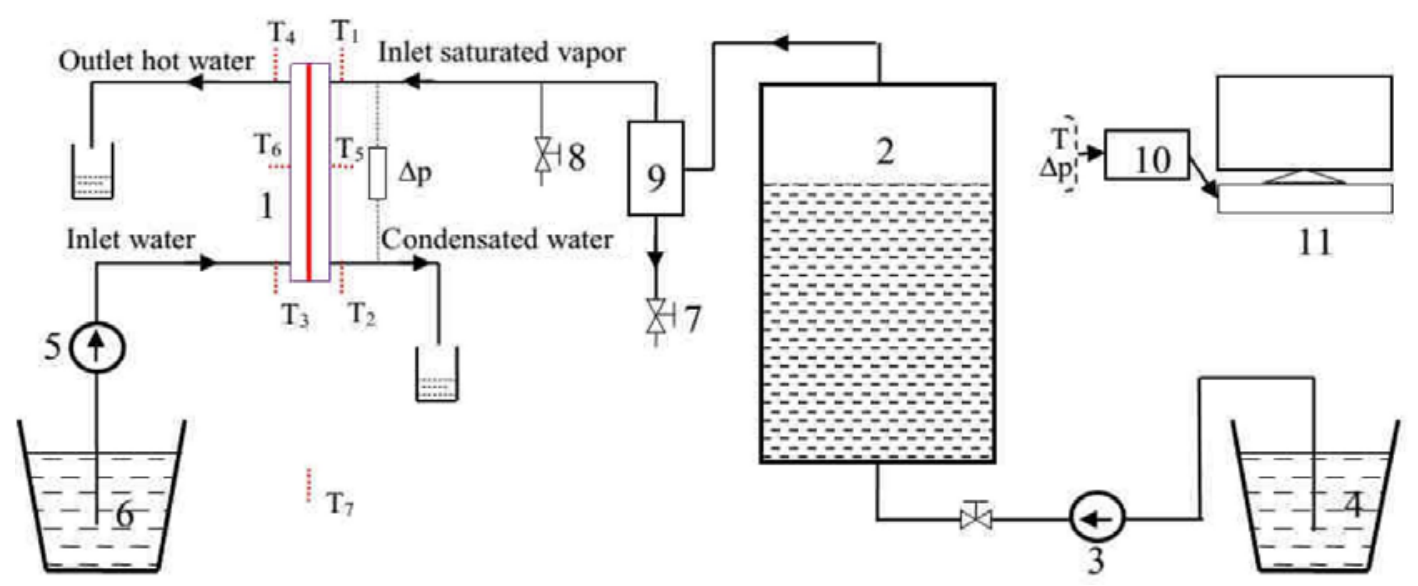

Figure 1. Schematic of the test loop for the models [16].
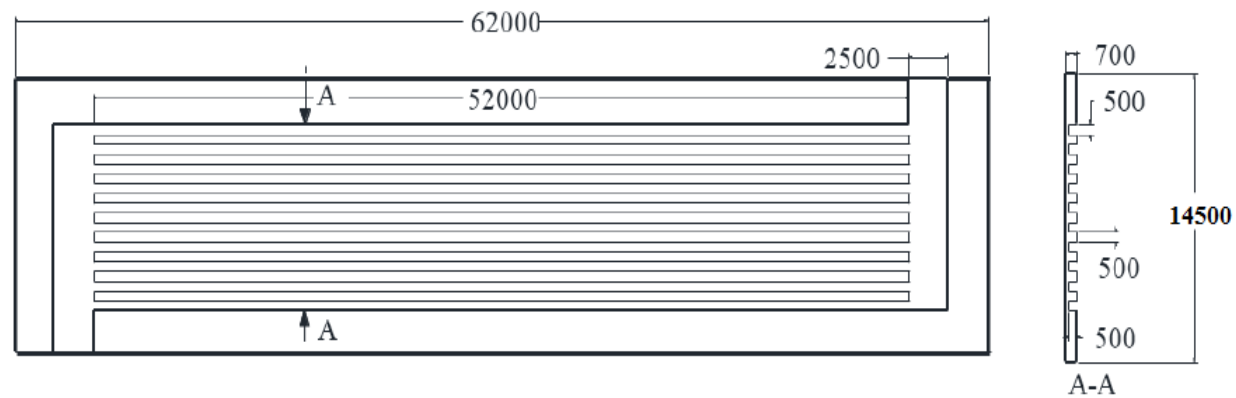

(a) Dimensions of the test section $(\mu \mathrm{m})$

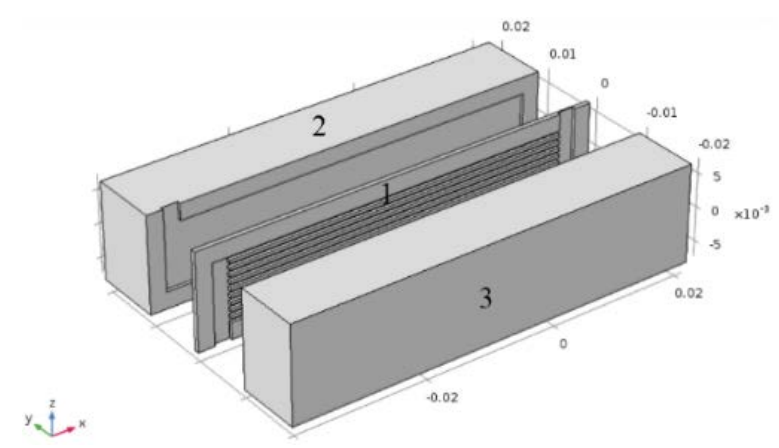

(b) Microchannel condenser (1) was pasted by two PMMA plates

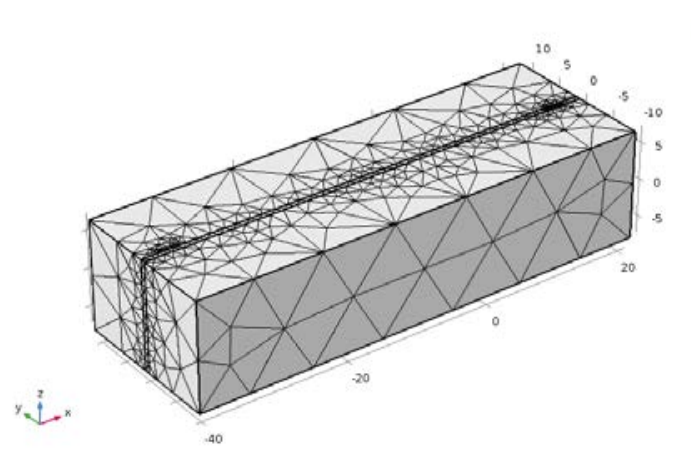

(c) Meshing results

Figure 2. Model for numerical simulation

\section{Results and Discussion}

\subsection{Temperature Profile}

With input parameters such as the steam temperature of $108^{0} \mathrm{C}$, steam mass flow rate $0.03 \mathrm{~g} / \mathrm{s}$ and cooling water flow rate $3 \mathrm{~g} / \mathrm{s}$, the numerical results solved the temperature profile as shown in Fig. 3. 


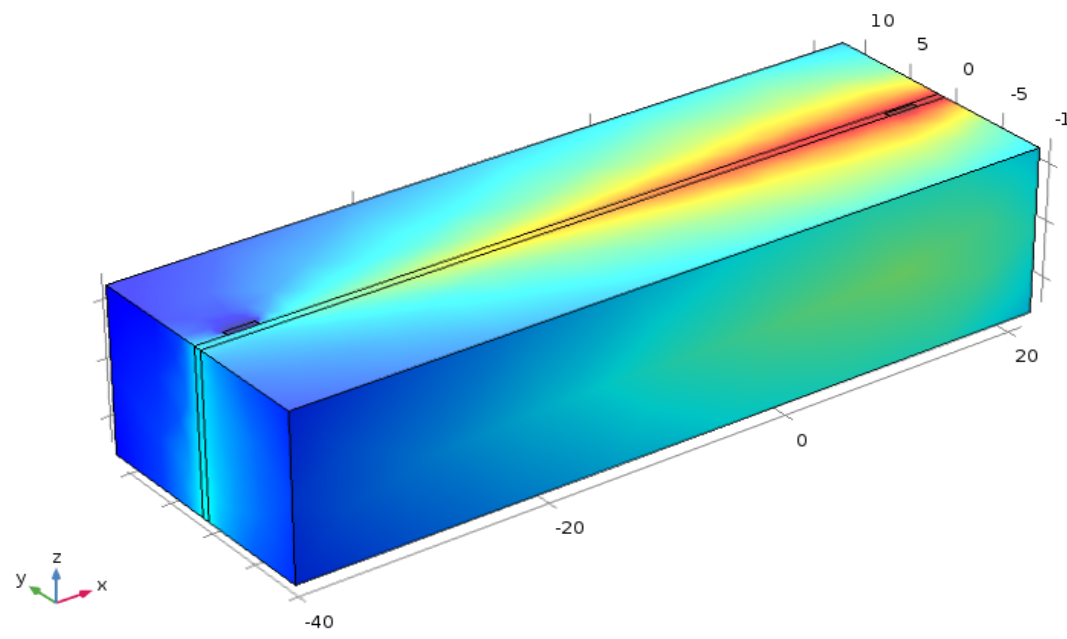

(a) 3D model
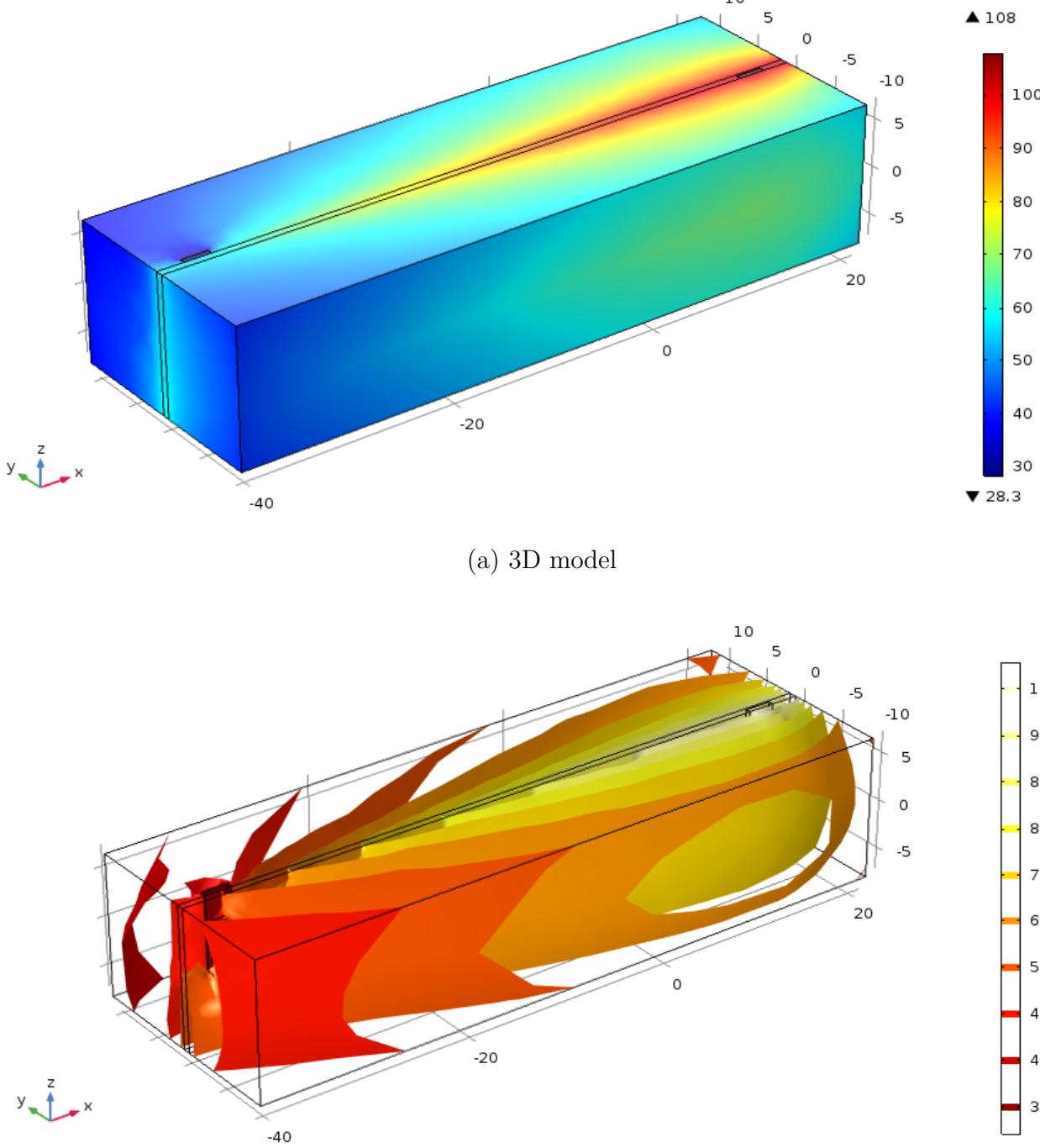

(b) Temperature profile distribution

Figure 3. The temperature profile of microchannel condenser.

The temperature profile distributions in Figs. 3a and 3b are in good agreement with input conditions: at the position of inlet steam, the temperature has the highest value and the temperature profile development is suitable the conduction equation for solid. Besides, the temperature profile development also demonstrated for a unification of heat transfer phenomena of the counter-flow heat exchanger in the test loop, as shown in Fig. 1.

The saturation steam flow rate is varying from $0.01 \mathrm{~g} / \mathrm{s}$ to $0.1 \mathrm{~g} / \mathrm{s}$ at the same vapor temperature of $105^{\circ} \mathrm{C}$ and cooling water temperature (with the cooling water temperature of $29^{\circ} \mathrm{C}$ and flow rate of $3 \mathrm{~g} / \mathrm{s}$, the results obtained having the outlet condensed water from $32^{\circ} \mathrm{C}$ to $73^{\circ} \mathrm{C}$, as shown in Fig. 4. The results indicated that the temperature of condensed water is a function of the steam mass flow rate as follow:

$$
\mathrm{t}=-1327.6 \mathrm{~m}^{2}+620.47 \mathrm{~m}+24.344, \text { with } \mathrm{R}^{2}=0.9981,{ }^{\circ} \mathrm{C} .
$$




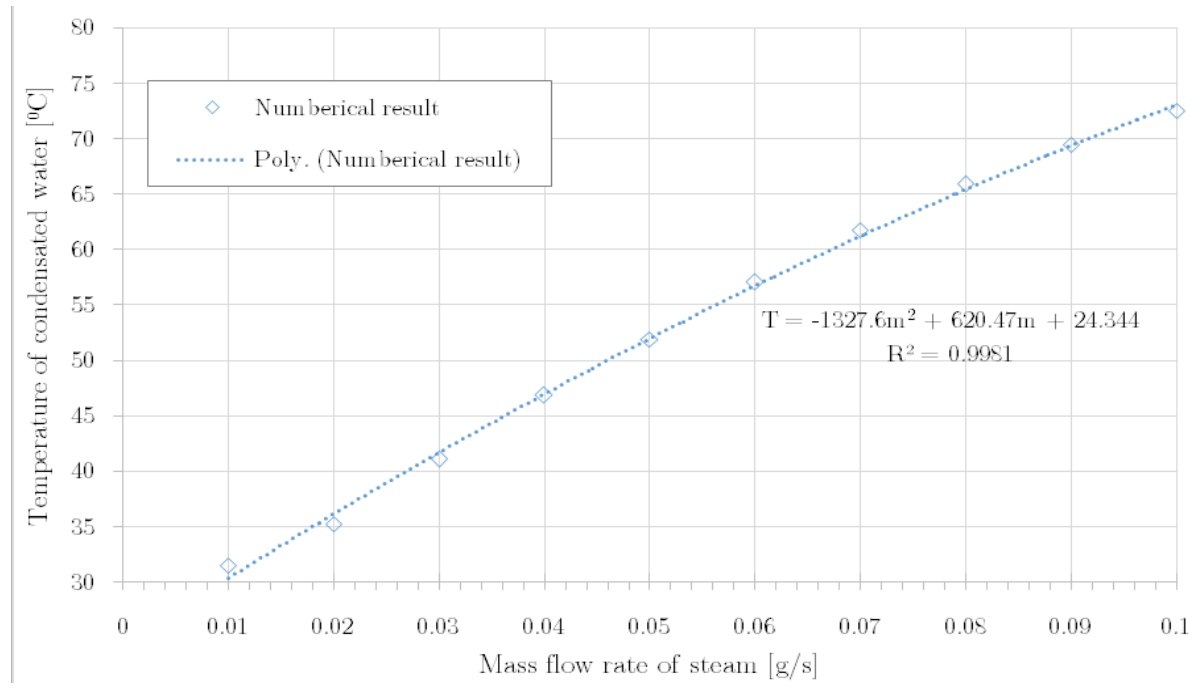

Figure 4. The temperature of condensed water vs. the mass flow rate of steam

\subsection{Steam Phase Change in Microchannels}

The results for phase change position from vapor to liquid in the microchannel condenser are shown in Fig. 5a, corresponding with steam inlet temperatures of $104^{\circ} \mathrm{C}$ and $107^{\circ} \mathrm{C}$ at the same steam flow rate of $0.07 \mathrm{~g} / \mathrm{s}$ and the cooling water temperature of $29^{\circ} \mathrm{C}$ at the water flow rate of $3 \mathrm{~g} / \mathrm{s}$. These results are obtained under the ambient temperature of $31^{\circ} \mathrm{C}$. The profile is in good agreement with the experimental results in Fig. 5b. The results indicated that the numerical simulations are in good agreement with the experimental data in [16].

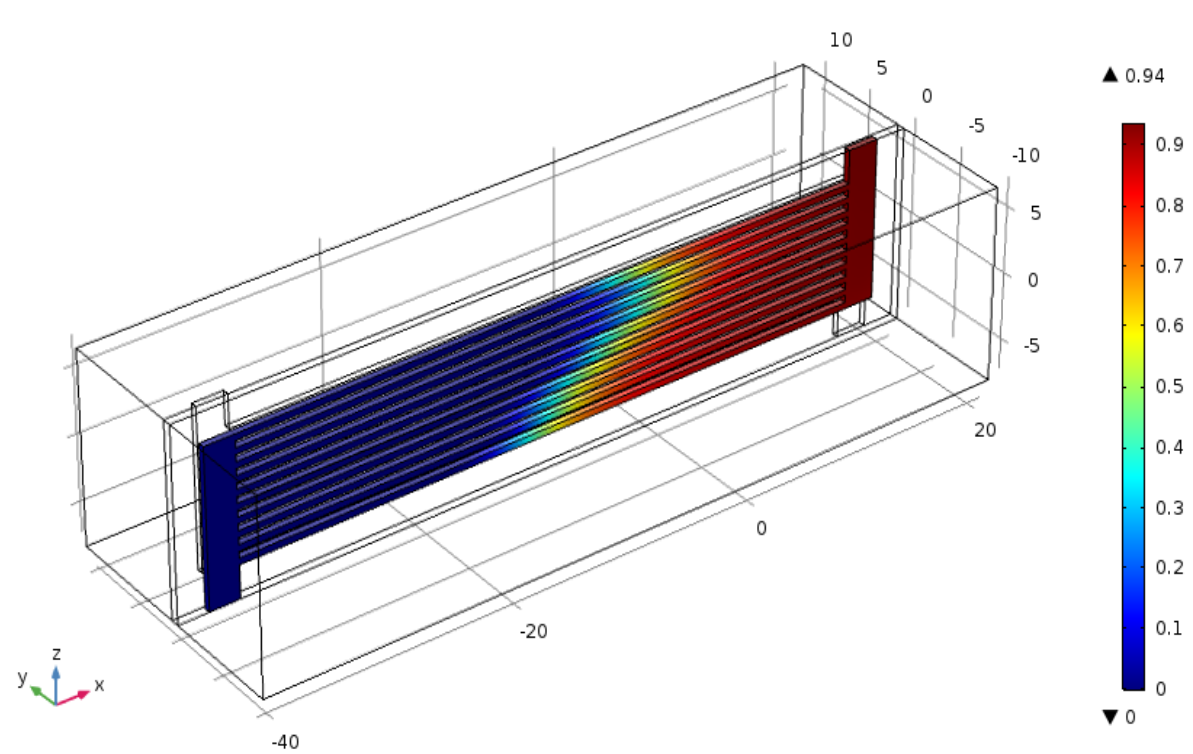

(a) Numerical result 


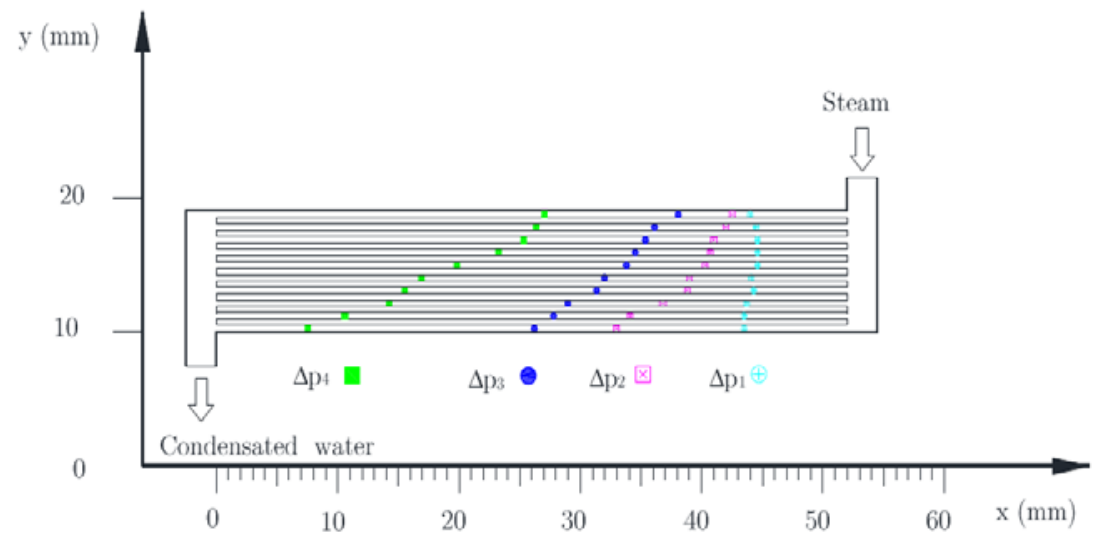

(b) Experimental data [16]

Figure 5. Profile of phase change.

\subsection{Density of Steam}

One of the parameters indicates the phase change from vapor to liquid is its density. The fluid density has a different change when it changes phase. Because the fluid in vapor status has small density and it has high density in liquid status.

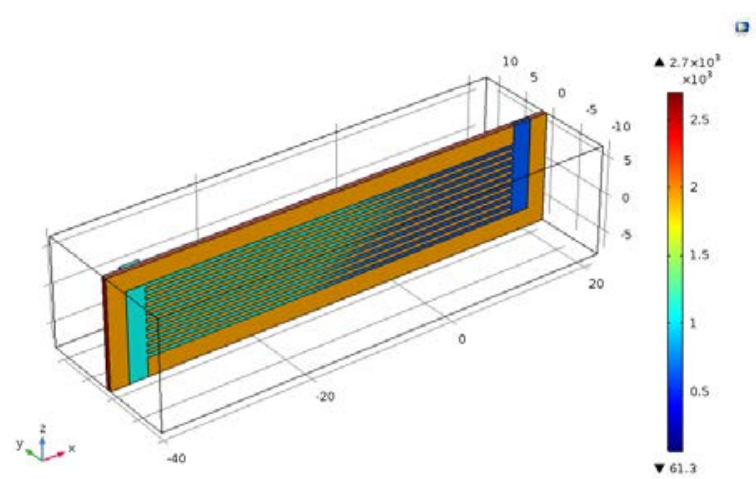

(a) Horizontal microchannels

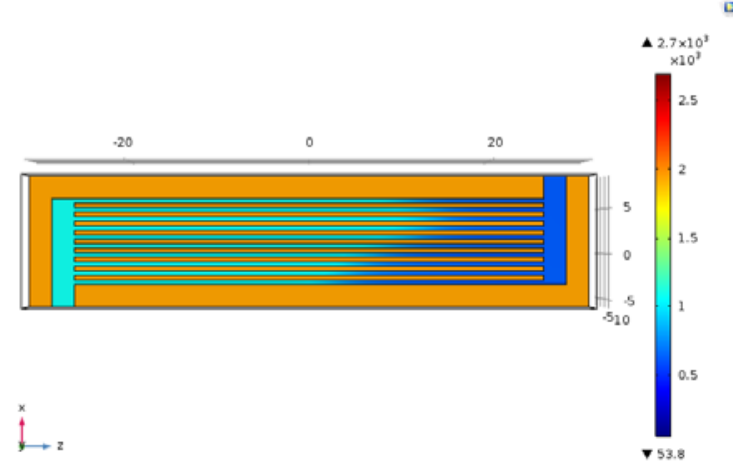

(b) Vertical microchannels

Figure 6. Density change for horizontal and vertical directions.

To evaluate the effects of gravity on condensation profile, a numerical comparison of microchannels between two cases for horizontal and vertical directions is shown in Fig. 6. The Figure 6a is the case for horizontal microchannel (the fluid direction is perpendicular to the gravity force) and Figure $6 \mathrm{~b}$ is the case for vertical microchannel (the fluid movement is the same direction with the gravity force). In the figure, the z-direction is the direction of gravity force in the Cartesian coordinates. It is observed that the condensation profile in this model is not strongly affected by the gravitational force, it only strongly depends on the arrangement method for moving fluid.

\section{Conclusions}

A study on the phase change heat transfer of steam in microchannel condenser has been done by the 3D numerical simulation for whole exchanger, using COMSOL Multiphysics 5.2a. The results indicate 3D temperature profile for entire condenser. Based on the results in this study, a function was suggested for predicting a relationship between the temperature of condensed water and the mass flow rate of steam from $0.01 \mathrm{~g} / \mathrm{s}$ to $0.1 \mathrm{~g} / \mathrm{s}$. 
Moreover, the numerical results show the profile of phase change from vapor to liquid in the microchannel condenser. The numerical results of profile were verified by the experiments for the same condition. The results of numerical simulation are in good agreement with the experimental data.

In addition, a numerical comparison of microchannels between two cases for horizontal and vertical directions has been presented also. The results showed that the condensation profile is not strongly affected by the gravitational force.

Acknowledgments. The supports of this work by the project No. T2017-TĐ (sponsored by the specific research fields at Hochiminh City University of Technology and Education, Vietnam) are deeply appreciated.

\section{References}

1. Asadi et al, "A review of heat transfer and pressure drop characteristics of single and two-phase microchannels", International Journal of Heat and Mass Transfer 79 (2014) 34-53.

2. Xia et al, "Investigation of the enhancement effect of heat transfer using micro channel", The 7th International Conference on Applied Energy ICAE2015.

3. T.T. Dang and J. T. Teng, "Comparisons of the heat transfer and pressure drop of the microchannel and minichannel heat exchangers", Heat Mass Transfer 47 (2011) 1311-1322.

4. T.T. Dang et al, "A study on the simulation and experiment of a microchannel counter-flow heat exchanger"Applied Thermal Engineering 30 (2010) 2163-2172.

5. T.T. Dang et al, "Numerical and Experimental investigations for effect of gravity to the heat transfer and fluid flow phenomena of microchannel heat exchangers", Applied International Journal of Computational Engineering Research 2 (2012) 260-270

6. X.F Yu et al, "A study on the hydraulic and thermal characteristics in fractal tree-like microchannels by numerical and experimental methods ", International Journal of Heat and Mass Transfer 55 (2012) 7499-7507.

7. M. Fossa, "A simple model to evaluate direct contact heat transfer and flow characteristics in annular two-phase flow", 655 Avenue of the Americas, New York, NY 10010.

8. H.G. Hu and C. Zhang, A modified k- $\varepsilon$ turbulence model for the simulation of two-phase flow and heat transfer in condensers, International Journal of Heat and Mass Transfer, 50 (2007) 1641-1648.

9. X. Ding, W. Cai, P. Duan, and J. Yan, Hybrid dynamic modeling for two phase flow condensers, Applied Thermal Engineering 62 (2014) 830-837.

10. P. Mirzabeygi and C. Zhang, Three dimensional numerical model for the two phase flow and heat transfer in condensers, International Journal of Heat and Mass Transfer 81 (2015) 618-637.

11. P. Mirzabeygi and C. Zhang, Turbulence modeling for the two phase flow and heat transfer in condensers, International Journal of Heat and Mass Transfer 89 (2015) 229-241.

12. S.Chen, Z. Yang, Y. Duan, Y. Chen, and D. Wu, Simulation of condensation flow in a rectangular microchannel, Chemical Engineering and Processing 76 (2014) 60-69.

13. K.Ling, G.Son, D.L Sun, and W.Q. Tao, Three dimensional numerical simulation on bubble growth and merger in microchannel boiling flow, International Journal of Thermal Science 98 (2015) 135-147.

14. Hicham El Mghari, Mohamed Asbik, Hasna Louahlia-Gualous, Ionut Voicu, Condensation heat transferenhancement in a horizontal non-circularmicrochannel, Applied Thermal Engineering 64 (2014) 358-370.

15. COMSOL Multiphysics, Heat transfer Module User's Guide, Chapter 4 -Theory for the heat transfer module, COMSOL 5.2a.

16. Minhhung Doan and Thanhtrung Dang, An experimental investigation on condensation in horizontal microchannels, International Journal of Civil, Mechanical and Energy Science 2 (2016) 99-106. 